\title{
IMPROVING RELIABILITY OF PRODUCT SUBJECTED TO RANDOM VIBRATION DURING TRANSPORTATION
}

\author{
SEONG-WOO WOO \\ Director and Chief Researcher, Reliability Association of Korea, Korea
}

\begin{abstract}
To enhance the reliability of newly designed product like refrigerator subjected to random vibrations in transportation, new reliability methodology, including load analysis and parametric Accelerated Life Testing (ALT), was presented. As a case study, refrigerator subjected to random vibration during transportation is studied to improve reliability. In first parametric ALT, the reliability of refrigerators was targeted to have B1 life in transportation. We found to be the damage of the compressor rubber mounts and the fractured connecting tubes between the compressor and condenser. The shape of failures in $1^{\text {st }}$ ALT and the failed samples in field are the same. The failures of connecting tube were caused by the design flaws of the compressor rubber mount. To correct these problems, the rubber mounts and the connecting tube were reshaped to protect the refrigerator from random vibration. Because there were no problems in $2^{\text {nd }}$ ALT, we knew that parametric ALTs were effective and the refrigerator was guaranteed to have B1 life in transportation.
\end{abstract}

Keywords: reliability design, random vibration, parametric accelerated life testing, missing design parameter.

\section{INTRODUCTION}

Typically, product in transportation travels from one location to another by vehicle like train or automobile. In the process product is continuously subjected to random vibrations from roads. In transportation, the reliability design of product like refrigerator is bound up in the random stresses that the product might experiences during its product lifetime. The failure mechanics of product that might no longer be functioned come from the overstress or wearout stress due to random loads on the structure in transportation (Fig. 1).

To prevent the product failure, mechanical engineers should know the characteristics of random loads. Therefore, they would move design flaws in the structure to location away from if there is design weak point in the structure where the loads are applied. Engineer can protect the product from damaging the product functions in transportation, though the random loads depend on the modes of transport.

Random vibration in transportation generates all frequencies within the given repeated limit cycles at the same time.A typical pattern of repeated load or overloading may cause structural failure in product lifetime. Many engineers think such possibility can be assessed: 1) mathematical modeling like Newtonian method, 2) the time response of system simulation for (random) dynamic loads, 3) the rain-flow counting method, and 4) miner's rule that the system damage can be estimated. However, because there are a lot of assumptions, this analytic methodology is exact but complex to reproduce the product failures due to the design flaws in transportation.

As another approach for random vibration, robust design skills like Taguchi methods and statistical design experiment (SDE) [1]-[6] also were studied by engineers and statisticians many years ago. Especially, Taguchi's robust design method utilizes parameter design to place it in a location where random noise factors do not cause effects, and determines the critical design parameters and their proper levels. 


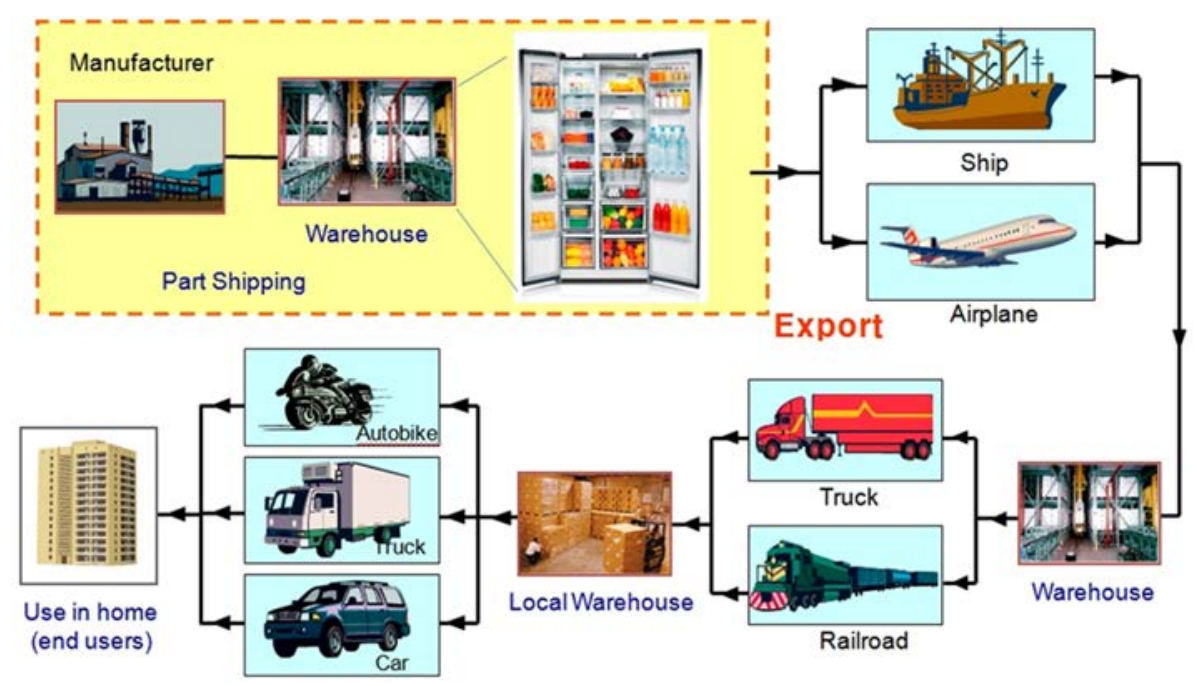

Figure 1: Product in transportation.

Through using interactions between control factors and noise factors, the basic idea of parameter design is to identify the proper control factors that make the system's performance robust in relation to changes in the noise factors. As a result, when the control factors are assigned to an inner array factor, the noise factors are assigned to an outer array factor in many of the orthogonal matrix that Taguchi has emphasized.

However, as the noise array is calculated repeatedly for every row in the control array repetitive, experimental iterations in the Taguchi product array would require a lot of computing time. Because a mechanical structure has complex shape, Taguchi method may claim infinite iterations. Though a mechanical structure is simple, it is hard to find it solutions in the robust design process. Newly designed refrigerator with the missing design parameters may result in reliability disasters and pay the huge quality costs.

In this study we suggest a new parametric Accelerated Life Testing (ALT) method that can make better the reliability design of newly designed product in transportation. This methodology will contain load analysis and parametric Accelerated Life Testing (ALT) with corrective action plans. We will find out the missing design parameters of product. It also will benefit to confirm the final design of product under the environmental conditions like transportation.

\section{LOAD ANALYSIS}

To evaluate the ride quality of product mounted on vehicle like train or automobile, the most useful mathematical model of a vehicle suspension system is a quarter car model [7]. Though it is two DOF and four state variables, it serves the purpose of figuring out the vehicle motion in transportation. The assumed model of the vehicle consists of the sprung mass and the unsprung mass, respectively. The sprung mass $m_{s}$ represents $1 / 4$ of the body of the vehicle, and the unsprung mass $m_{u s}$ represents one wheel of the vehicle. The main suspension is modeled as a spring $k_{s}$ and a damper $c_{s}$ in parallel, which connects the unsprung to the sprung mass. The tire (or rail) is modeled as a spring $k_{u s}$ and represents the transfer of the road force to the unsprung mass (Fig. 2) 


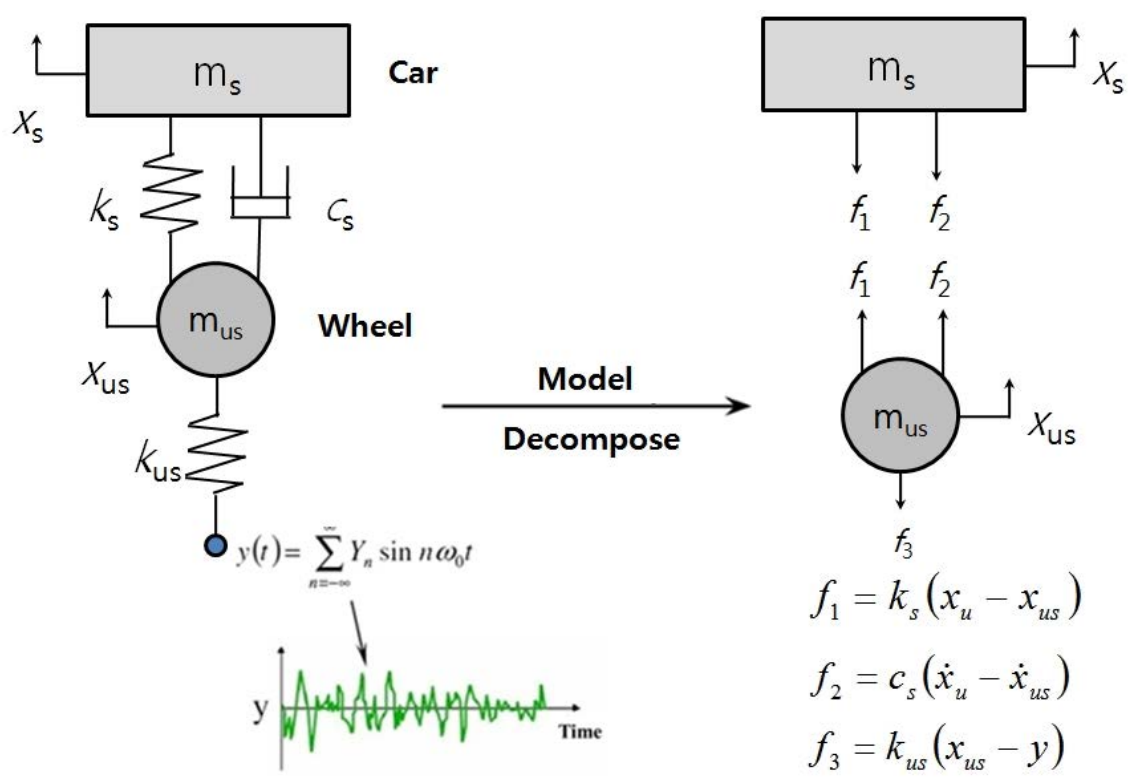

Figure 2: A quarter car model and its decomposition.

The governing differential equations of motion for the quarter car model can be represented as:

$$
\begin{gathered}
m_{s} \ddot{x}_{s}+c_{s}\left(\dot{x}_{s}-\dot{x}_{u s}\right)+k_{s}\left(x_{s}-x_{u s}\right)=0 \\
m_{u s} \ddot{x}_{u s}+c_{s}\left(\dot{x}_{u s}-\dot{x}_{s}\right)+\left(k_{u s}+k_{s}\right) x_{u s}-k_{s} x_{s}=k_{u s} y
\end{gathered}
$$

So, the above equations of motion can be concisely represented as:

$$
\left[\begin{array}{cc}
m_{s} & 0 \\
0 & m_{u s}
\end{array}\right]\left[\begin{array}{c}
\ddot{x}_{s} \\
\ddot{x}_{u s}
\end{array}\right]+\left[\begin{array}{cc}
c_{s} & -c_{s} \\
-c_{s} & c_{s}
\end{array}\right]\left[\begin{array}{c}
\dot{x}_{s} \\
\dot{x}_{u s}
\end{array}\right]+\left[\begin{array}{cc}
k_{s} & -k_{s} \\
-k_{s} & k_{u s}+k_{s}
\end{array}\right]\left[\begin{array}{c}
x_{s} \\
x_{u s}
\end{array}\right]=\left[\begin{array}{c}
0 \\
k_{u s} y
\end{array}\right]
$$

As a result, eqn (3) can be expressed in a matrix form

$$
[M] \ddot{X}+[C] \dot{X}+[K] X=F
$$

When eqn (4) is numerically integrated, we can obtain the time response of the state variables due to random vibration and transform the power spectral density (PSD) in frequency domain (Fig. 3). 

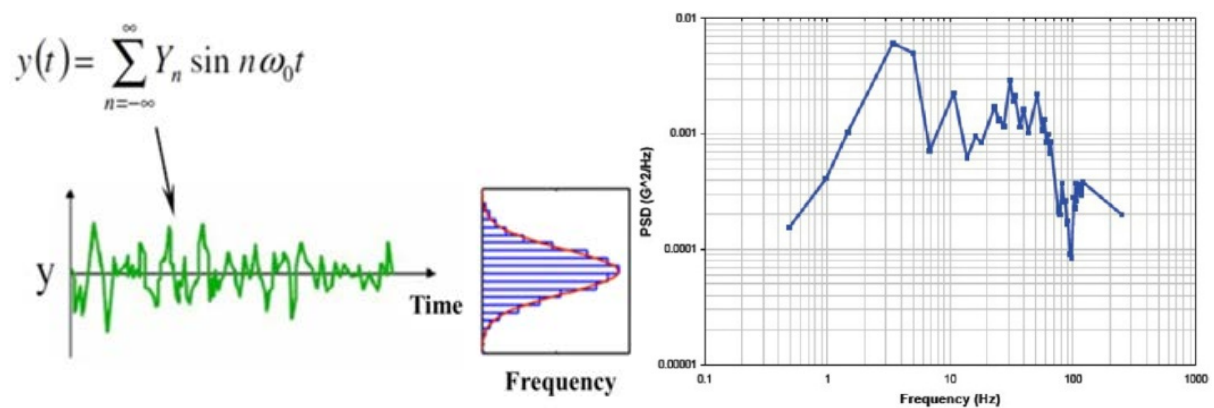

Figure 3: (a) Base random vibrations; (b) Typical intermodal random vibration.

Product in transportation would ride on a rough road or rail, wave height on the water. The random vibrations in field are that the higher amplitude is the smaller frequency. On the other hands, the lower amplitude is the larger frequency. We can say it follows the normal distribution (Fig. 3(a)). If response of quarter car model displays in frequency domain, we can obtain the plot of power spectral density like Fig. 3(b) that is the usual way to specify random vibration. We can judge the amplitude of the natural frequency of product when random vibration is transmitted from road in transportation.

The force transmitted to the product can be expressed as Q [8]:

$$
Q=\frac{F_{T}}{k Y}=r^{2}\left[\frac{1+(2 \zeta r)^{2}}{\left(1-r^{2}\right)^{2}+(2 \zeta r)^{2}}\right]
$$

Because the stress of the product in transportation comes from the transmitted vibration load $\left(F_{T}\right)$ from the basis, the general life-stress model (LS model) [9] can be modified as:

$$
T F=A(S)^{-n}=A(F)^{-\lambda}
$$

The acceleration factor $(A F)$ can be represented as the product of the amplitude ratio of acceleration $R$ and force transmissibility $Q$. That is,

$$
A F=\left(\frac{S_{1}}{S_{0}}\right)^{n}=\left(\frac{F_{1}}{F_{0}}\right)^{\lambda}=\left(\frac{a_{1}}{a_{0}} \frac{F_{T}}{k Y}\right)^{\lambda}=(R \times Q)^{\lambda}
$$

\section{PARAMETRIC ACCELERATED LIFE TESTING (ALT) OF PRODUCT}

To derive the sample size equation and parametric ALT, characteristic life $\eta$ should be estimated from Weibull distribution. First of all, the characteristic life $\eta_{M L E}$ from the Maximum Likelihood Estimation (MLE) can be derived as:

$$
\eta_{M L E}^{\beta}=\sum_{i=1}^{n} \frac{t_{i}^{\beta}}{r}
$$


If the confidence level is $100(1-\alpha)$ and the number of failure is $r \geq 1$, the characteristic life, $\eta_{\alpha}$, would be estimated from eqn (8),

$$
\eta_{\alpha}^{\beta}=\frac{2 r}{\chi_{\alpha}^{2}(2 r+2)} \cdot \eta_{M L E}^{\beta}=\frac{2}{\chi_{\alpha}^{2}(2 r+2)} \cdot \sum_{i=1}^{n} t_{i}^{\beta} \quad \text { for } \mathrm{r} \geq 1
$$

If there is no failures, $p$-value is $\alpha$ and In $(1 / \alpha)$ is mathematically equivalent to Chi-Squared value, $\frac{\chi_{\alpha}^{2}(2)}{2}$. The characteristic life $\eta_{\alpha}$, would be expressed as:

$$
\eta_{\alpha}^{\beta}==\frac{2}{\chi_{\alpha}^{2}(2)} \cdot \sum_{i=1}^{n} t_{i}^{\beta}=\frac{1}{\ln \frac{1}{\alpha}} \cdot \sum_{i=1}^{n} t_{i}^{\beta} \quad \text { for } \mathrm{r}=0
$$

Because eqn (9) is established for all cases $r \geq 0$, it can be redefined as:

$$
\eta_{\alpha}^{\beta}=\frac{2}{\chi_{\alpha}^{2}(2 r+2)} \cdot \sum_{i=1}^{n} t_{i}^{\beta} \quad \text { for } \mathrm{r} \geq 0
$$

From the Weibull reliability function, we can find out that the characteristic life can be converted into $L_{B}$ life as:

$$
R(t)=e^{-\left(\frac{L_{B X}}{\eta}\right)^{\beta}}=1-x
$$

After logarithmic transformation, eqn (12) can be expressed as:

$$
L_{B X}^{\beta}=\left(\ln \frac{1}{1-x}\right) \cdot \eta^{\beta}
$$

If the estimated characteristic life of $p$-value ${ }_{\alpha} \eta, \alpha$, in eqn (11), is substituted into eqn (13), we obtain the $B X$ life equation:

$$
L_{B X}^{\beta}=\frac{2}{\chi_{\alpha}^{2}(2 r+2)} \cdot\left(\ln \frac{1}{1-x}\right) \cdot \sum_{i=1}^{n} t_{i}^{\beta}
$$

For a $60 \%$ confidence level, the first term $\frac{\chi_{\alpha}^{2}(2 r+2)}{2}$ in eqn (14) can be approximated to $(r+1)$ [10]. By Taylor expansion, if the cumulative failure rate, $x$, is below 20 percent, the second term $\ln \frac{1}{1-x}$ approaches to $x$., it can be represented as:

$$
L_{B X}^{\beta}=\frac{1}{r+1} \cdot x \cdot \sum_{i=1}^{n} t_{i}^{\beta}
$$


Most lifetime testing has insufficient samples. The allowed number of failures would not have as much as that of the sample size.

$$
\sum_{i=1}^{n} t_{i}^{\beta}=\sum_{i=1}^{r} t_{i}^{\beta}+(n-r) h^{\beta} \geq(n-r) h^{\beta}
$$

If eqn (16) is substituted into eqn (15), the BXlife equation can be modified as follows:

$$
L_{B X}^{\beta} \geq \frac{1}{r+1} \cdot x \cdot(n-r) h^{\beta} \geq L_{B X}^{* \beta}
$$

Then, sample size equation with the number of failure can also be modified as:

$$
n \geq(r+1) \cdot \frac{1}{x} \cdot\left(\frac{L_{B X}^{*}}{h}\right)^{\beta}+r
$$

From the sample size eqn (18), we can go on parametric ALT testing under any failure conditions $(r \geq 0)$. Consequently, it also confirms whether the failure mechanism and the test method are proper.

If the acceleration factors in eqn (7) are replaced with the planned testing time $h$, eqn (18) will be modified as:

$$
n \geq(r+1) \cdot \frac{1}{x} \cdot\left(\frac{L_{B X}^{*}}{A F \cdot h_{a}}\right)^{\beta}+r
$$

\section{RELIABILITY DESIGN OF REFRIGERATOR SUBJECTED TO RANDOM VIBRATION DURING TRANSPORTATION}

In the field, as the compressor rubber mounts in the mechanical compartments of refrigerators were damaging, the connecting tubes are fracturing under uninformed rail conditions. According to the market survey, the distance of first failure in transportation was approximately $2500 \mathrm{~km}$ in 2 days. In Chicago the $27 \%$ among whole transported products were roughly failed. For 7 days, when the refrigerator travelled $7200 \mathrm{~km}$ that is total distance from Los Angles to Boston, the $67 \%$ of whole products were fractured (Fig. 4).

As seen in Fig. 5, refrigerator is made up of condenser, capillary tube, evaporator, and compressor. As refrigerating cycle transfers heat from the internal room of the refrigerator to the surrounding, refrigerator can store fresh or frozen food. To sell the refrigerator, after producing in factory, refrigerator is transported to the end-user by transportation means - air, rail, road, and water. When refrigerators are travelled by train or automobile, they are subjected to random vibration loads. These random vibrations from the base in transportation are continually transmitted to the refrigerators. Product like refrigerator uses compressor rubber mounts to protect the random vibration. If inappropriately designed, refrigerators eventually don't work under the continual random vibration. Eventually, the refrigerators should be designed to outlive the damage that may happen during transport. 


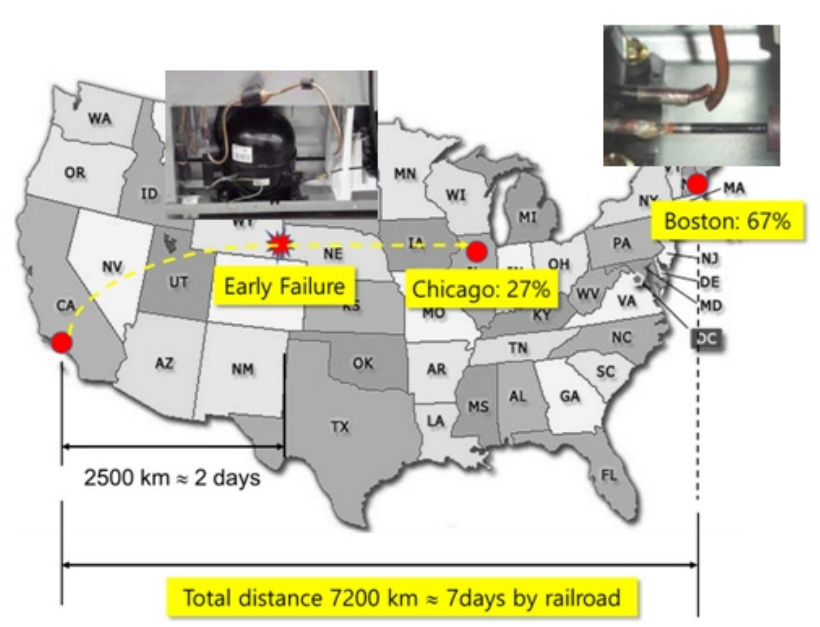

Figure 4: Failed locations in the field.
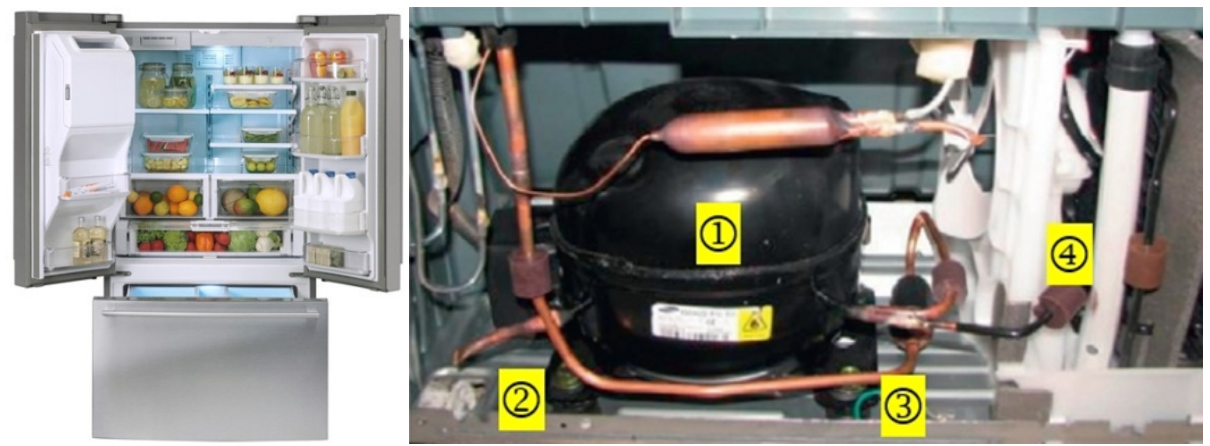

Figure 5: Residential-sized refrigerator and mechanical compartment. (a) Residentialsized refrigerator; (b) Mechanical compartment: (1) compressor, (2) rubber, (3) connecting tubes, and (4) fan and condenser.

However, if improperly designed, refrigerator was continuously subjected to random vibration in transportation, the tubes were fracturing. Refrigerant therefore was leaking out of the tubes and missing of refrigerating capacity. Field data also showed that the failed refrigerators might have had design defects that prevented protection from random vibration during transportation. These design flaws could cause a crack to occur, and thus result in failure. After reproducing the failed refrigerator in laboratory test, the root cause of design should be exactly found.

The reliability of refrigerator in laboratory testing was targeted to be less than B1 life during total distance from Los Angles to Boston. Based on the field data, the rail transportation was expected to move a refrigerator $2,500 \mathrm{~km}$ in 2 days. For a total travel transportation distance of 7 days, the refrigerator moved 7,200 km from Los Angeles to Boston. From eqn (7), the acceleration factor is the product of the amplitude ratio of acceleration $R$ and force transmissibility $Q$. 


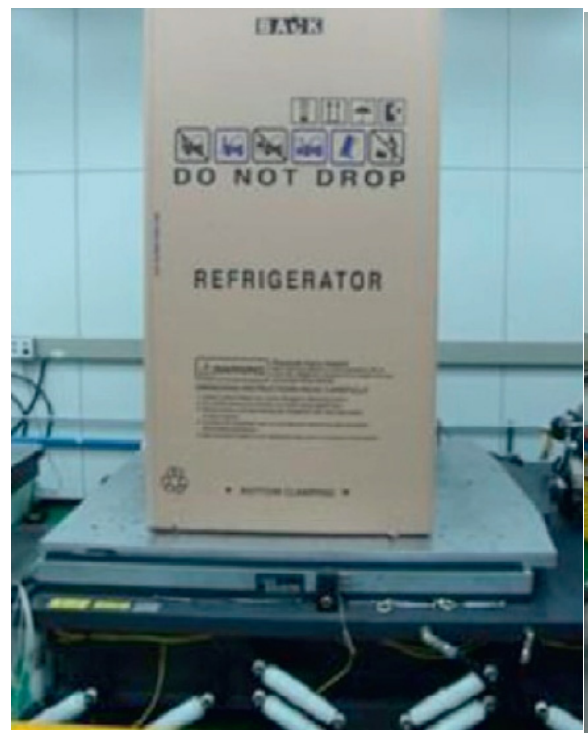

(a) Horizontal vibration (Left $\leftrightarrow$ Right)

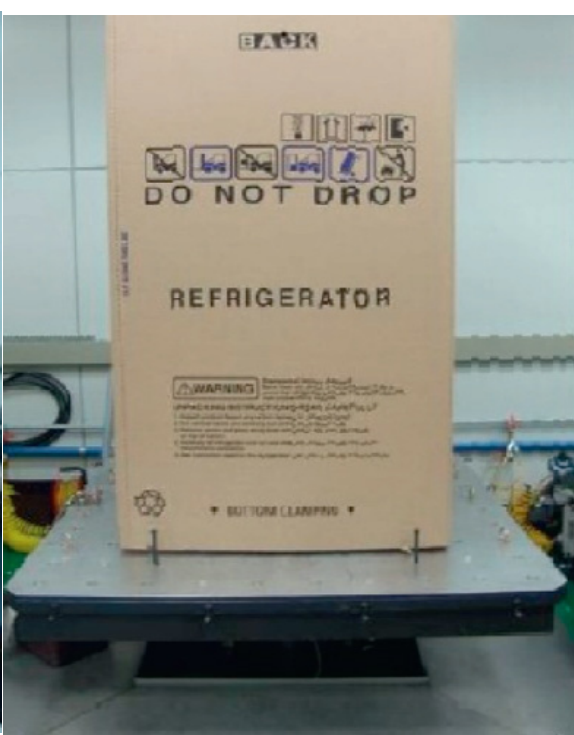

(b) Vertical vibration (Up $\leftrightarrow$ Down)

Figure 6: Vibration test equipment for the accelerated life tests.

Table 1: ALT Conditions for accelerated testing of the refrigerator.

\begin{tabular}{l|l|l|l}
\hline System Conditions & Worst Case & ALT & AF \\
\hline \hline Transmissibility, $Q(r=1.0, \zeta=0.1)$ & - & $\begin{array}{l}5.1 \\
\text { (From eqn. (5) })\end{array}$ & 5.11 \\
\hline Amplitude ratio of acceleration, $R\left(a_{1} / a_{0}\right)$ & $0.24 g$ & $1 g$ & 4.17 (2) \\
\hline Total $\left.A F(=(1) \times(2))^{2}\right)$ & & & 452 \\
\hline
\end{tabular}

To obtain accelerated factor, when the refrigerator was given to an acceleration of $1 \mathrm{~g}$ on a shaker table, we could find that the natural frequency of horizontal vibration (left $\leftrightarrow$ right) was $5 \mathrm{~Hz}$. On the other hand, the natural frequency of vertical vibration (up $\leftrightarrow$ down) was $9 \mathrm{~Hz}$ in the package test (Fig. 6). Supposed that natural frequency $(r=1.0)$ and small damping ratio $(\zeta=0.1)$ were given, the force transmissibility had a value of approximately 5.1 from eqn (5). The amplitude ratio of acceleration was 4.17. Using accumulative damage exponent of 2.0, we knew that the acceleration factor was found to be 452.0 (Table 1).

The required testing time for three samples can be obtained from eqn (19) if reliability target and accelerated factor are given. Supposed that the shape parameter in the Weibull chart was 2.0, the test time obtained from eqn (19) were approximately 130 min for 3 pieces, respectively. For total travel distance $7200 \mathrm{~km}$ (5 days), if the refrigerator fails less than once during $130 \mathrm{~min}$ that makes up the reliability quantitative (RQ) test specifications, refrigerator in transportation was designed to ensure B1 life with about a $60 \%$ level of confidence. 


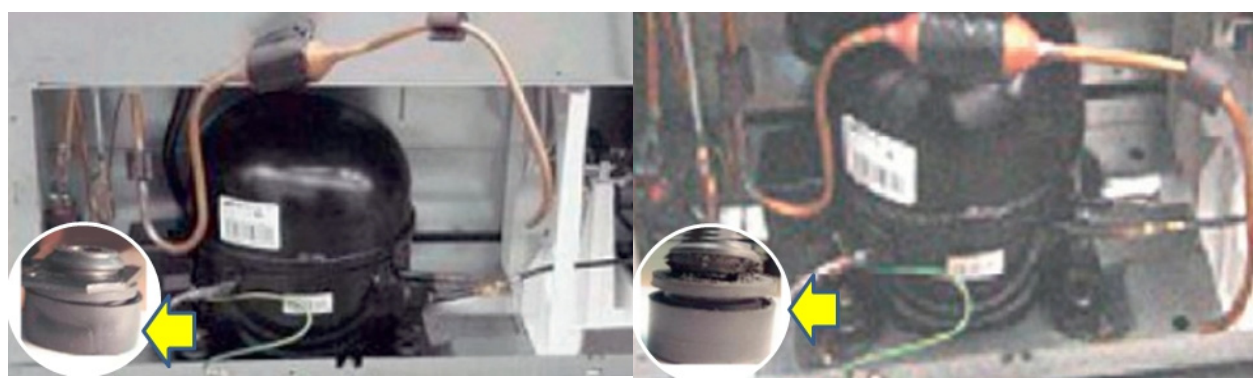

(a) Field

(b) $1^{\text {st }}$ ALT Results

Figure 7: Failure of refrigerator tubes in the field and 1st ALT result.

Three refrigerators in $1^{\text {st }}$ parametric ALT were fractured from horizontal vibration (left $\leftrightarrow$ right) until 40 minutes. Fig. 7 shows the failed products from the field and the fractured samples from the ALT, respectively. The photos show that the shapes and locations of the failures in the ALT were similar to those seen in field.

A graphical analysis of the ALT results and field data on Weibull plot were shown in Fig. 8. From the Weibull plot, the shape parameter finally was obtained to be 6.13. As seen in Fig. 9(a), the tearing in the first ALT occurred because of no support shape of the rubber mount for $\mathrm{X}$ axis vibration (left $\leftrightarrow$ right). Parametric ALT was valid in pinpointing the design weaknesses that were responsible for the failures in field.

The design flaws of the refrigerator came from the shape of the compressor rubber and connecting tube design. Fractured tubes between the compressor and condenser areas could be corrected by modifying the shape of the compressor rubber mount and the connecting tube design.

The rubber in refrigerator was reshaped as follows: 1) a redesigned compressor rubber mount shape, $\mathrm{C} 1$ and 2) a redesigned connecting tube shape, $\mathrm{C} 2$. With these modified parameters, second ALTs for refrigerator were performed. The design targets of the newly designed samples were less than the target life of a B1 life for total travel distance (5days). The confirmed values of AF and $\beta$ in Table 1 and Fig. 8 were 452.0 and 6.41 , respectively.

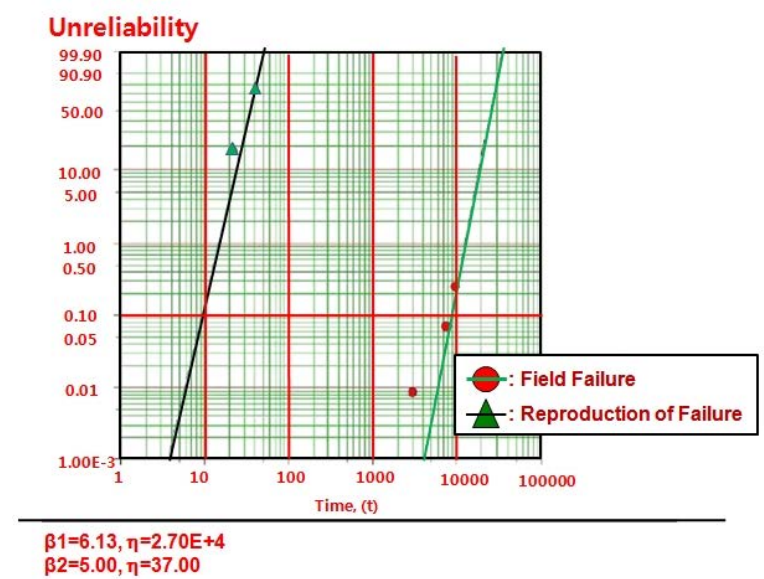

Figure 8: Failure of refrigerator tubes in the field and 1stALT result. 


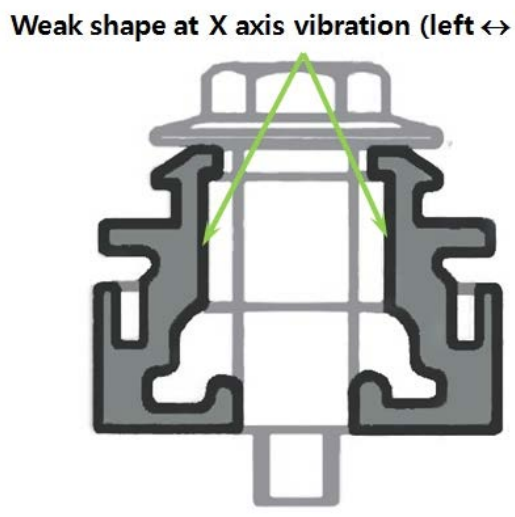

(a) Initial design

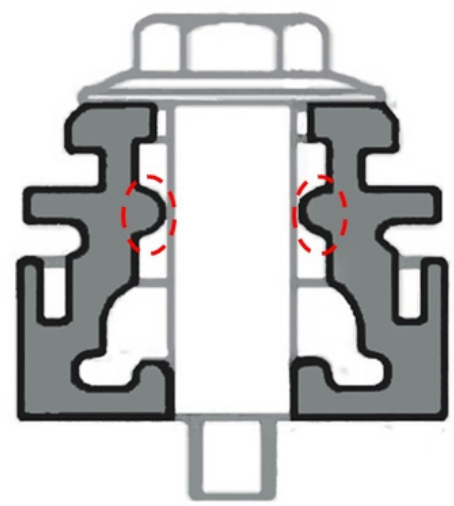

(b) Modified design

Figure 9: Problematic rubber in refrigerator.

The recalculated test time in eqn (19) for three sample pieces were $40 \mathrm{~min}$. In the second ALT, because the refrigerators were not fractured until $60 \mathrm{~min}$, we knew that the modified designs were effective to protect the refrigerator from the random vibrations.

Table 2: Results of ALTs.

\begin{tabular}{lll}
\hline & $1^{\text {st }}$ ALT & $2^{\text {nd }}$ ALT \\
\cline { 2 - 3 } & Initial Design & Final Design \\
\hline In 40 min, & \\
fracture of the & 20 min: $1 / 3$ fracture & $40 \mathrm{~min}: 3 / 3 \mathrm{OK}$ \\
connecting tube & 40 min: $2 / 3$ fracture & $60 \mathrm{~min}: 3 / 3 \mathrm{OK}$ \\
in refrigerator is & & \\
less than 1 & & \\
\hline
\end{tabular}

Machine room in refrigerator

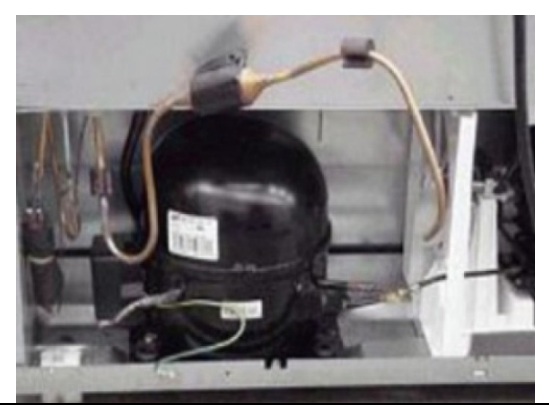

specification

C1: Shape of the compressor rubber

$\mathrm{C} 2$ : Connecting tube shape 
Table 2 summarized the results of the ALTs. Through two rounds of ALTs, the modified refrigerators with the targeted B1 life were expected to survive without failure in transportation.

\section{CONCLUSIONS}

New reliability methodologies were suggested to improve the reliability design of product subjected to random vibration loads in transportation. These reliability methodologies contained load analysis including its dynamic modeling, parametric Accelerated Life Testing (ALT), and corrective action plans for the new product. As a case study, reliability design of refrigerator subjected to random vibration during transportation was studied. To reproduce the failed product in the field, we conducted load analysis and a series of parametric ALTs. Based on the products that failed both in the field and in the ALTs, the primary failure of the refrigerators occurred due to the tearing of the compressor rubber mount. As a result, the tubes between the compressor and condenser were fractured. The refrigerator was redesigned from the root cause of failed sample and its action plans.

The primary missing design parameters of the refrigerator were the shape of compressor rubber mount for $\mathrm{X}$ axis vibration, and then secondary came from the vulnerable structure of the connecting tubes. The corrective action plans reshaped the compressor rubber mount and the connecting tube. There was no failure in the second ALT because the design modifications were effective. After a sequence of ALTs, the proper values for the design parameters were guaranteed to meet the life cycle requirements-B1 life for total transportation distance $7200 \mathrm{~km}$, respectively. Inspection of the failed product, load analysis, and two rounds of parameter ALTs showed that the product reliability - the newly designed residential refrigerator was greatly improved. Another case study of this new reliability testing methodology [11]-[20], will be recommended.

\section{REFERENCES}

[1] Taguchi, G., Off-line and on-line quality control systems. In: Proceedings of the International Conference on Quality Control, Tokyo, Japan, 1978.

[2] Taguchi, G. \& Shih-Chung. T., Introduction to quality engineering: bringing quality engineering upstream. New York: American Society of Mechanical Engineering, 1992.

[3] Ashley S., Applying Taguchi's quality engineering to technology development. Mechanical Engineering, 1992.

[4] Wilkins, J., Putting Taguchi methods to work to solve design flaws, Quality Progress, 33(5), pp. 55-59, 2000.

[5] Phadke, M., Quality engineering using robust design. Englewood Cliffs (NJ): Prentice Hall, 1989.

[6] Byrne, D. \& Taguchi, S., The Taguchi approach to parameter design. Quality Progress, 20(12), pp. 19-26, 1987.

[7] Jazar, R., Vehicle Dynamics: Theory and Application, Springer, pp. 931-975, 2008.

[8] Rao, S., Mechanical Vibrations,4th ed., New York: Prentice Hall, 2003.

[9] McPherson, J., Accelerated testing, packaging, electronic materials handbook, ASM International 1, pp. 887-894, 1989.

[10] Ryu, D. \& Chang, S., Novel Concept for Reliability Technology, Microelectronics Reliability, 45(3), pp. 611-622, 2005.

[11] Woo, S., \& Pecht, M., Failure analysis and redesign of a Helix upper dispenser, Engineering Failure Analysis, 15(4), pp. 642-653, 2008. 
[12] Woo, S., O’Neal, D. \& Pecht, M., Improving the reliability of a water dispenser lever in a refrigerator subjected to repetitive stresses, Engineering Failure Analysis, 16(5), pp. 1597-1606, 2009.

[13] Woo, S., O’Neal, D. \& Pecht, M., Design of a hinge kit system in a Kimchi refrigerator receiving repetitive stresses, Engineering Failure Analysis, 16(5), pp. 1655-1665, 2009.

[14] Woo, S., Ryu, D. \& Pecht, M., Design evaluation of a French refrigerator drawer system subjected to repeated food storage loads, Engineering Failure Analysis, 16(7), pp. 2224-2234, 2009.

[15] Woo, S., O’Neal, D. \& Pecht, M., Failure analysis and redesign of the evaporator tubing in a Kimchi refrigerator, Engineering Failure Analysis, 17(2), 369-379, 2010.

[16] Woo, S., O’Neal, D. \& Pecht, M., Reliability design of a reciprocating compressor suction reed valve in a common refrigerator subjected to repetitive pressure loads, Engineering Failure Analysis, 17(4), pp. 979-991, 2010.

[17] Woo, S., Pecht, M. \& O’Neal, D., Reliability design and case study of a refrigerator compressor subjected to repetitive loads, International Journal of Refrigeration, 32(3), pp. 478-486, 2009.

[18] Woo, S., The reliability design of mechanical system and its Parametric ALT. Handbook of Materials Failure Analysis with Case Studies from the Chemicals, Concrete and Power Industries. Elsevier, pp. 259-276, 2015.

[19] Woo S. \& O'Neal, D., Reliability design of mechanical systems subject to repetitive stresses, Recent Patents on Mechanical Engineering, 8(4), pp. 222-234, 2015.

[20] Woo, S., Reliability Design of Mechanical Systems: A Guide for Mechanical and Civil Engineers, 1st ed., Springer, 2017. 